DOI: https://doi.org/10.24127/ajpm.v9i3.2793

\title{
PRE-SERVICE MATHEMATICS TEACHERS' METACOGNITIVE BELIEFS AND THEIR EFFECT ON MATHEMATICS ANXIETY
}

\author{
Hendra Kartika $^{1 *}$, Lessa Roesdiana ${ }^{2}$ \\ ${ }^{1 *, 2}$ Universitas Singaperbangsa Karawang, Karawang, Indonesia \\ ${ }^{*}$ Corresponding author. HS. Ronggowaluyo Road East Telukjambe, 41361, Karawang, West Java, Indonesia. \\ E-mail: $\quad$ hendra.kartika@staff.unsika.ac.id ${ }^{\left.{ }^{*}\right)}$ \\ lessa.roesdiana@fkip.unsika.ac.id ${ }^{2)}$
}

Received 03 May 2020; Received in revised form 07 September 2020; Accepted 16 September 2020

\begin{abstract}
The present study aimed to identify the effects of metacognitive beliefs on mathematics anxiety encompassed by pre-service mathematics teachers'. The intervention role of factors such as positive beliefs was also examined. For this purpose, a total of sixty college students from the mathematics education program of one of the public universities in Indonesia were investigated through cross-sectional surveys. The data of the research were collected through a students' self-report measure of metacognitive beliefs and mathematics anxiety. The results reveal that although there is no gender difference in metacognitive beliefs, female students are more anxious in mathematics than male students. There are no year levels of difference in metacognitive beliefs and mathematics anxiety. The result shows that metacognitive beliefs have negatively correlated with math anxiety. This study concludes that developing metacognitive beliefs helps pre-service mathematics teachers to effectively overcome mathematics anxiety. Also, enhancing cognitive confidence and controlling negative beliefs about the uncontrollability of thoughts and danger has implications as a treatment to reduce mathematics anxiety.
\end{abstract}

Keywords: Mathematics anxiety; metacognitive beliefs; pre-service teachers.

This is an open access article under the Creative Commons Attribution 4.0 International License

\section{INTRODUCTION}

Recently, metacognitive beliefs are likely to become an important component in mental health, particularly to anxiety. Metacognitive beliefs may play in the development and maintenance of health anxiety symptoms (Melli, Bailey, Carraresi, \& Poli, 2017). Ostefjells et al (2017) suggest that metacognitive beliefs may be important criteria for anxiety treatment. In relation to social anxiety, research so far has shown that metacognitive beliefs are positively contributing to social anxiety both directly and indirectly, through cognitive processes (Gkika, Wittkowski, \& Wells, 2018).
Metacognitive beliefs are beliefs about thinking that refers to general worry and thoughts. According to Palmier-Claus, Dunn, Morrison, \& Lewis (2011), metacognitive beliefs are irrational and unrealistic demands imposed on individuals' own thoughts. In this respect, metacognitive beliefs could be described as how people control, monitor, measure, and manage their cognition about worry and thoughts. Furthermore, concerning erroneous beliefs about thinking, content domains of metacognitive beliefs can be divided into positive and negative. Positive metacognitive beliefs represent the beliefs of an individual about the utility of certain cognitive enterprises (e.g. "worrying about danger 
will mean I'm always prepared"), while negative metacognitive beliefs represent the beliefs of an individual about the risk or uncontrollability of thoughts (e.g. "my thoughts will cause harm") (Sellers, Gawęda, Wells, \& Morrison, 2016). Several studies have indicated that metacognitive beliefs could be linked to the nature of emotion disorder symptoms (Reinholdt-Dunne et al., 2019), psychological disorder, and general anxiety rather than to precise diagnoses (Sellers, Varese, Wells, \& Morrison, 2017). However, very little is known about the metacognitive beliefs correlates with mathematics anxiety.

Mathematics anxiety is an anxiety disorder in mathematics and in mathematical situations. These situations may involve daily activities in which individuals have to deal with numbers as well as academic issues (Cipora, Szczygiel, Willmes, \& Nuerk, 2015). Additionally, It is a condition in which individuals suffer from the pathological fear of mathematics to the point that they are hindered in their reasoning and are incapable of understanding or being comfortable in mathematics (Gresham, 2018). According to (Luttenberger, Wimmer, \& Paechter, 2018) math anxiety may found in three facets: test, classroom, and numerical anxiety.

In addition, anxiety with mathematics is a widespread, worldwide problem affecting all age groups (Luttenberger et al., 2018), gender differences, and all level of education. It is a common problem in education, prompting commitment from both educators and researchers to help students achieve their full academic potential (Ramirez, Shaw, \& Maloney, 2018). However, relatively little is identified about mathematics anxiety as encountered over time by pre-service mathematics teachers, or how to eliminate it. Hence, to better understand and evaluate this important topic and the impact to which it exists and interacts with its mathematics lessons, current research conducted with preservice mathematics teachers is required.

According to the rationales presented above, the purpose of this study was to explore relations between metacognitive beliefs and mathematics anxiety among pre-service mathematics teachers' regarding gender differences and years level.

\section{RESEARCH METHOD}

The research employed quantitative descriptive through crosssectional surveys. This approach was used to collect information that represents the behaviors, habits, thoughts, and values of the participants at the same time.

The sample was selected through convenience sampling from 60 preservice mathematics teachers, enrolled in a pre-service mathematics education program from the University of Singaperbangsa Karawang in Western Indonesia. Forty-four of these participants were female and sixteen were male. The sample consisted of 20 first years, 20 second years, and 20 third years. Table 1 shows the number of participants for each year level and gender.

Table 1. The number of participants and their gender at each year level.

\begin{tabular}{cccccc}
\hline \multirow{2}{*}{ No } & \multirow{2}{*}{ Gender } & \multicolumn{3}{c}{ Year Level } & \multirow{2}{*}{ Total } \\
\cline { 3 - 5 } & & $\mathbf{1}$ & $\mathbf{2}$ & $\mathbf{3}$ & \\
\hline 1 & Male & 5 & 6 & 5 & 16 \\
2 & Female & 15 & 14 & 15 & 44 \\
3 & Total & 20 & 20 & 20 & 60 \\
\hline
\end{tabular}


The metacognitive beliefs of participants were assessed with the metacognitions questionnaire (MCQ30). The Metacognition Questionnaire30 (MCQ-30) tests maladaptive metacognitive beliefs considered fundamental to the psychopathology metacognitive model (Huntley et al., 2020). This questionnaire contains 30 , in which 4-point Likert-type items $(1=$ Strongly disagree, 4 = Strongly agree). The questionnaire contains five correlated but conceptually separate measures that test three areas of positive and negative metacognitive beliefs, metacognitive control, and cognitive trust judgments. The five subscales are: (1) "cognitive confidence (assessing confidence in attention and memory)", (2) "positive beliefs about worry", (3) "cognitive self-consciousness (the tendency to focus attention on thought processes)", (4) "negative beliefs about thoughts concerning uncontrollability and danger", and (5) "negative beliefs concerning the consequences of not controlling thoughts".

"A modified version of the Abbreviated Math Anxiety Scale" (AMAS) was employed to assess participants' mathematics anxiety. It was a self-report questionnaire containing a total of nine items. Participants use a 4-point Likert scale to show their anxiety during certain mathrelated situations $(1=$ not at all anxious to $4=$ very anxious).

The students optionally to participate in the study, but all students agreed to participate. The questionnaires were constructed using paper and pencil, which took approximately 15 minutes to complete. It was administered to students at the end of the learning period before students face the final semester exams in the classroom environment.
The data analysis was performed using IBM SPSS Statistics 20. While analyzing the data, nonparametric tests were used because the types of data are ordinal. Mann-Whitney U test was used to compare metacognitive beliefs and mathematics anxiety based on gender. As shown as in Table 2, the data did provide criteria for the test of homogeneity of variances. P-value was found as $0.445(p>0.05)$ for metacognitive beliefs; $0.130(p>0.05)$ for mathematics anxiety.

Table 2. Test of Homogeneity of variances of metacognitive beliefs and mathematics anxiety by gender.

\begin{tabular}{ccccc}
\hline & $\begin{array}{c}\text { Levene } \\
\text { Statistic }\end{array}$ & df1 & df2 & p \\
\hline MB & .592 & 1 & 58 & $0.445^{*}$ \\
MA & 2.356 & 1 & 58 & $0.130^{*}$ \\
\hline
\end{tabular}

Note: $\mathrm{MB}=$ metacognitive beliefs, $\mathrm{MA}=$ mathematics anxiety. ${ }^{*} p>0.05$

Kruskal-Wallis test was used to compare metacognitive beliefs and mathematics anxiety based on year level. The data provided parameters for the estimation homogeneity of variances. As shown in Table 3, p-value was found to be $0.244(p>0.05)$ for metacognitive beliefs, while $p$-value was found to be $0.149(p>0.05)$ for mathematics anxiety.

Table 3. Test of Homogeneity of variances of metacognitive beliefs and mathematics anxiety by year level.

\begin{tabular}{ccccc}
\hline & Levene Statistic & df1 & df2 & p \\
\hline MB & 1.445 & 2 & 57 & $0.244^{*}$ \\
MA & 1.966 & 2 & 57 & $0.149^{*}$
\end{tabular}

Note: ${ }^{*} p>0.05$ 
Futhermore,

Spearman's correlation analysis was used to test negative or positive effects between metacognitive beliefs and mathematics anxiety as well as to find the most important metacognitive beliefs factors on mathematics anxiety. In this analysis, mathematics anxiety was the dependent variable, while the independent variable was metacognitive beliefs.

\section{RESULTS AND DISCUSSION}

Gender Differences in Metacognitive Beliefs and Mathematics Anxiety

To examine whether there were differences between the participants in the gender variable, the Nonparametric Independent Samples Mann-Whitney U test was used. The result of MannWhitney $U$ can be seen in Table 4 .

Table 4. Mann-Whitney U test results by gender.

\begin{tabular}{cccc}
\hline & $\begin{array}{c}\text { Mann- } \\
\text { Whitney } \mathbf{U}\end{array}$ & $\mathbf{z}$ & $\mathbf{p}$ \\
& 288.000 & -1.072 & 0.284 \\
MB & 237.500 & -1.923 & $0.055^{*}$ \\
MA & & &
\end{tabular}

Mann-Whitney U test results highlighted that the metacognitive beliefs variable $(0.284)$ is more than $0.050 \quad(p>0.005)$. These results indicated that there was no evidence of gender difference was found in terms of metacognitive beliefs. Regarding the mathematics anxiety variable, results showed that the p-value (0.055) is approximately equal to 0.050 . Thus, it can be inferred that $p$-value $=0.055$ is close to being statistically significant. There were significant differences in mathematics anxiety between females and males. As shown in Table 5, the mean rank of a male is lower than females. These results indicated that the mathematics anxiety of female participants was more anxious in mathematics than male participants.

Table 5. Mean rank by gender.

\begin{tabular}{lllll}
\hline & Gender & N & $\begin{array}{c}\text { Mean } \\
\text { Rank }\end{array}$ & $\begin{array}{c}\text { Sum of } \\
\text { Ranks }\end{array}$ \\
\hline MB & Male & 16 & 34.50 & 552.00 \\
& Female & 44 & 29.05 & 1278.00 \\
& Total & 60 & & \\
MA & Male & 16 & 23.34 & 373.50 \\
& Female & 44 & 33.10 & 1456.50 \\
& Total & 60 & & \\
\hline
\end{tabular}

Years of Level Differences in Metacognitive Beliefs and Mathematics Anxiety

Kruskal-Wallis Test was used to investigate significant statistical differences between the participants' metacognitive beliefs and mathematics anxiety at the year level. The participants' concerning year levels were: first, second, and third. However, the Kruskal-Wallis test indicated that there were no significant years of level differences $(p>0.05)$ in the relationship between metacognitive beliefs and mathematics anxiety. Table 6 presents the Kruskal-Wallis test results concerning the year level.

Table 6. Kruskal-Wallis test by year level.

\begin{tabular}{cccc}
\hline & Chi-Square & df & p \\
\hline MB & 0.415 & 2 & 0.813 \\
MA & 0.025 & 2 & 0.988 \\
\hline
\end{tabular}


DOI: https://doi.org/10.24127/ajpm.v9i3.2793

The Effect of Metacognitive Beliefs on Mathematics Anxiety

The way to know the effect metacognitive beliefs on mathematics anxiety used Spearman Rho correlations. It based on the number of the sample $(n=60)$ were conducted to determine if there is a correlation between metacognitive beliefs and mathematics anxiety. The metacognitive beliefs scores were found to have a statistically significant, negative relationship with mathematics anxiety ( $r=-0.409, p<0.05)$. The participants whose metacognitive beliefs score was high, they had less anxious in mathematics than the students with a low score in metacognitive beliefs.

\section{Metacognitive Beliefs Factors} Influencing Mathematics Anxiety

The correlations analysis was carried out using Spearman Rho to determine the influence of metacognitive beliefs factors on mathematics anxiety. As shown in Table 7 , there was a significant negative correlation between cognitive confidence and mathematics anxiety ( $r$ $=-0.381, p<0.01)$, the correlation of uncontrollability and danger and mathematics anxiety was significant negative ( $r=-0.384, p<0.01)$, and need control thoughts was also significantly negatively correlated with uncontrollability and danger $(r=-0.312$, $p<0.05)$.

Table 7. Correlations among metacognitive beliefs and mathematics anxiety.

\begin{tabular}{lcccccc}
\hline & $\mathbf{1}$ & $\mathbf{2}$ & $\mathbf{3}$ & $\mathbf{4}$ & $\mathbf{5}$ & $\mathbf{6}$ \\
\hline 1. Mathematics Anxiety & 1 & $-0.381^{* *}$ & 0.001 & -0.216 & $-0.384^{* *}$ & 0.082 \\
2. Cognitive Confidence & & 1 & 0.076 & 0.000 & 0.150 & 0.133 \\
3. Positif Beliefs & & & 1 & -0.101 & -0.165 & 0.169 \\
4. Cognitive Self- & & & & 1 & 0.117 & -0.039
\end{tabular}

Consciousness

5. Uncontrollability and

Danger

6. Need Control Thoughs

Note: ${ }^{* *}$ Correlation is significant at the 0.01 level (2-tailed). ${ }^{*}$ Correlation is significant at the 0.05 level (2-tailed).

Anxiety in mathematics is viewed as a multidimensional construct (Artemenko et al., 2015). Additionally, there are three elements raise our concern to determine the influence of metacognitive beliefs and the most significant factors with mathematics anxiety, namely: cognitive elements (e.g., worry), attitudinal (e.g., dislike), and emotional (e.g., fear). Besides, the study measured the metacognitive beliefs scores and indicated the relationship between gender, year level, and mathematics anxiety.

The current study showed that female students more anxious than male students, whereas they are moderately equal in metacognitive beliefs score. Current results are generally consistent with the majority of results of previous 
studies addressing gender differences in adolescence and adult in levels of math anxiety, which described that female individual's higher levels than male (e.g., Devine, Fawcett, Szucs, \& Dowker, 2012; Hembree, 1990; Jansen, Schmitz, \& van der Maas, 2016) and there are the absence of gender differences regarding metacognitive beliefs scores (e.g., Lenzo et al., 2016).

The gender gap may vary due to the characteristics of the sample (age, years level, and culture). There was a higher percentage of females in our sample compared with males. At each year's level, approximately $75 \%$ of students are female. The relatively high percentage of females may account for part of the gender gap observed in this study. At least two plausible theories. Either female in our sample was not chosen based on their academic interest in undertaking a pre-service mathematics education program. The two most popular reasons chosen by female students were that they motivated by their parents and that they felt teaching would bring high job satisfaction. More Indonesian parents argue that the teaching profession is a good profession for female careers and life choices, resulting in more teaching jobs and possibly also reflected in higher math anxiety. Consequently, work and gender may be challenging. An alternative explanation would be that females tend to be ranked themselves lower and show more anxiety about mathematics in the current study. Note that also in general females tend to report higher levels of anxiety (e.g., Hantsoo \& Epperson, 2017).

Furthermore, the result reported that mathematics anxiety and metacognitive beliefs covering years level comparatively equal. Furthermore, metacognitive beliefs have a negative influence on mathematics anxiety. Hence, it could be said that the higher students' metacognitive beliefs, the lower level of the students' mathematics anxiety. Result also revealed that cognitive confidence and uncontrollability and danger were the most elements of metacognitive beliefs contributing to mathematics anxiety, in contrast to studies which found metacognitive beliefs in uncontrollability, advantages, and avoidance of worry may contribute to the increased prevalence of anxiety in high school samples (Bahrami \& Yousefi, 2011). Although our results differ slightly, it could nevertheless be argued that students with high cognitive confidence and high uncontrollability and danger of thoughts tend to obtain lower in mathematics anxiety.

\section{CONCLUSION AND SUGGESTION}

This paper has given an account of pre-service mathematics teachers' metacognitive beliefs and mathematics anxiety regarding gender differences and years level. As we showed, female students often have the same level of metacognitive beliefs as male students. In contrast, we found that female students are substantially higher in mathematics anxiety than male students. Moreover, we have provided further evidence that a moderate negative correlation was observed between metacognitive beliefs and mathematics anxiety. These results might suggest that metacognitive beliefs may have the potential effect to reduce mathematics anxiety. Surprisingly, our research underlined the importance of cognitive confidence and uncontrollability and danger for students to overcome their mathematics anxiety. 
The limit of this study concerned the sample size and composition. On one hand, it is important to extend the research for more large sample size and in other universities. A challenging question for future research is to understand how the element of metacognitive beliefs may overwhelm anxiety about mathematics (e.g., cognitive confidence, uncontrollability and danger of thoughts). The results of these studies should serve as a guide to the interpretation of the personality characteristics of our pre-service mathematics teachers.

\section{REFERENCES}

Artemenko, C., Daroczy, G., \& Nuerk, H. C. (2015). Neural correlates of math anxiety-an overview and implications. Frontiers in Psychology, 6, 1333.

Bahrami, F., \& Yousefi, N. (2011). Females are more anxious than males: A metacognitive perspective. Iranian Journal of Psychiatry and Behavioral Sciences, 5(2), 83-90.

Castelnuovo, G., Simons, M., Gawe da, Ł., Gawe, da, G., Reinholdt-Dunne, M. L., Blicher, A., \& Wells, A. (2019). Modeling the Relationships Between Metacognitive Beliefs, Attention Control and Symptoms in Children With and Without Anxiety Disorders: A Test of the S-REF Model.

https://doi.org/10.3389/fpsyg.2019. 01205

Cipora, K., Szczygiel, M., Willmes, K., \& Nuerk, H. C. (2015). Math anxiety assessment with the Abbreviated Math Anxiety Scale: Applicability and usefulness: Insights from the polish adaptation. Frontiers in Psychology, 6(NOV), 1-16. https://doi.org/10.3389/fpsyg.2015. 01833

Devine, A., Fawcett, K., Szucs, D., \& Dowker, A. (2012). Gender differences in mathematics anxiety and the relation to mathematics performance while controlling for test anxiety. Behavioral and Brain Functions, 8, 1-9. https://doi.org/10.1186/1744-90818-33

Gkika, S., Wittkowski, A., \& Wells, A. (2018). Social cognition and metacognition in social anxiety: A systematic review. Clinical Psychology and Psychotherapy, 25(1), 10-30. https://doi.org/10.1002/cpp.2127

Gresham, G. (2018). Preservice to inservice: does mathematics anxiety change with teaching experience? Journal of Teacher Education, 69(1), 90-107. https://doi.org/10.1177/002248711 7702580

Hill, F., Mammarella, I. C., Devine, A., Caviola, S., Passolunghi, M. C., \& Szucs, D. (2016). Maths anxiety in primary and secondary school students: Gender differences, developmental changes and anxiety specificity. Learning and Individual Differences, 48(2015), 45-53.

https://doi.org/10.1016/j.lindif.201 6.02.006

Huntley, C. D., Young, B., Smith, C. T., Jha, V., \& Fisher, P. L. (2020). Assessing metacognitive beliefs in test anxiety: Psychometric properties of the metacognitions questionnaire, 30 (MCQ-30) among university students. Current Psychology, 30. https://doi.org/10.1007/s12144020-00662-y 
Jansen, B. R. J., Schmitz, E. A., \& van der Maas, H. L. J. (2016). Affective and motivational factors mediate the relation between math skills and use of math in everyday life. Frontiers in Psychology, 7(APR), 1-11. https://doi.org/10.3389/fpsyg.2016. 00513

Lenzo, V., Ellen, M., Tripodi, F., \& Quattropani, M. C. (2016). Gender Differences in Anxiety, Depression and Metacognition. In Z. Bekirogullari, M. Y. Minas, \& R. X. Thambusamy (Eds.), The European Proceedings of Social \& Behavioural Sciences EpSBS (pp. 1-16). Retrieved from http://www.futureacademy.org.uk/f iles/images/upload/1_4381_fullTex t_1_27.pdf

Luttenberger, S., Wimmer, S., \& Paechter, M. (2018). Spotlight on math anxiety. Psychology Research and Behavior Management, $\quad 11, \quad 311-322$. https://doi.org/10.2147/PRBM.S14 1421

Melli, G., Bailey, R., Carraresi, C., \& Poli, A. (2018). Metacognitive beliefs as a predictor of health anxiety in a self-reporting Italian clinical sample. Clinical Psychology and Psychotherapy, 25(2), 263-271. https://doi.org/10.1002/cpp.2159

Ostefjells, T., Lystad, J. U., Berg, A. O., Hagen, R., Loewy, R., Sandvik, L., \& Rossberg, J. I. (2017). Metacognitive beliefs mediate the effect of emotional abuse on depressive and psychotic symptoms in severe mental disorders. Psychological Medicine, 47(13), 2323-2333. https://doi.org/10.1017/S00332917 17000848
Palmier-Claus, J. E., Dunn, G., Morrison, A. P., \& Lewis, S. W. (2011). The role of metacognitive beliefs in stress sensitisation, selfesteem variability, and the generation of paranoia. Cognitive Neuropsychiatry, 16(6), 530-546. https://doi.org/10.1080/13546805.2 011.561583

Ramirez, G., Shaw, S. T., \& Maloney, E. A. (2018). Math Anxiety: Past Research, Promising Interventions, and a New Interpretation Framework. Educational Psychologist, 53(3), 145-164. https://doi.org/10.1080/00461520.2 018.1447384

Sellers, R., Gawęda, Ł., Wells, A., \& Morrison, A. P. (2016). The role of unhelpful metacognitive beliefs in psychosis: Relationships with positive symptoms and negative affect. Psychiatry Research, 246(October), 401-406. https://doi.org/10.1016/j.psychres.2 016.10.029

Sellers, R., Varese, F., Wells, A., \& Morrison, A. P. (2017). A metaanalysis of metacognitive beliefs as implicated in the self-regulatory executive function model in clinical psychosis. Schizophrenia Research, 179, 75-84. https://doi.org/10.1016/j.schres.201 6.09 .032 